The child presented a very curious appearance. The whole of the occipital, and both parietal bones, were wanting; there seemed to be no neck; and the fuce looked as if its lower halt were stuck between the clavicles; the posterior prortions of the cerebrum and cerebellum. and some of the upper portion of the spine too. seemed wanting. I was very anxious to secure the child. lint the friends resisted all my endeavours to examine it thorounhly. The limbs were pretematurally long; the child seemed well nourished, was at the full time, and had not been dead many hours. The placenta canne away naturally, and the wonuan did very well for some weeks; she then caught a severe cold, und died in three months of phthisis.

CASF, II. About 10 A.m., on June (ith, $185 \pi$, I was requested to see Mrs. M., aged :3\%, who was every day expecting her fifth child. She stated that she had not felt any murement for two days, and complained of a dull aching pain over the whole ab. dumen; the bowels were very loose, and she was suffering fron severe sichness. The abdomen was not larger than natural under the circumstances, and the pain did not seem increased by pressure. 'The most careful examination did not detect the sounds of the foetal heart, and there was no placental bruit. I told her I thought the child was dead, and ordered the following mixture.

Bo Confectionis aromatica $\mathrm{j} s \mathrm{~s}$; liquoris opii sedativi $m \times x i v$; xtheris chlorici $亏$ iss: syruni simplicis $\mathfrak{j}$ iij ; aqua cinnamomi ad $\zeta v j$. M. Fiat mistura, cujus capiat cochlearia ij magna 4tis horis.

She was somewhat better in the evening; but the bowels being still very loose, and the pain rather severe at times, I ordered $h+r$ to continue the medicine, and take the following pills at bedtime.

Bo Hydrargyri chloridi gr. iij; pilulæ saponis comp. gr. v. M. Fiant pilulæ ij.

She passed a very comfortable night. About ten o'clock the next day labour commenced, and the child, a female, was born just as I entered the house It presented almost the same appearances as the one in the last case; but it had been evidently dead longer, and was not so well nourished. The pla. centa caused considerably difficulty, so that after waiting an hour, I introduced my hand and took it away; the chord was very tender, and the placenta disorganised.

About three days afterwards she had an attack of peritonitis, which however speedily yielded to the usual treatment by leeches and calomel.

Case IIr. On Friday, October 9th, 1857, about 10 A.M., I was called on to attend Mrs. $H$. a young woman, aged 23 , ju her first confinement. On inquiry, I found that she had been poorly most of the night, and the membranes had ruptured about an hour previous to my coming in, discharging several quarts of liquor amnii. An examination showed the os uteri dilated to about the size of a shilling, high up, thick and cushiony, with pains about every half hour; but no presenting part could be felt. I left, giving directions to be sent for when the pains were more severe and frequent. I was again sent for about eight o'clock in the evening, and on examination found what at first struck me as being a shoulder; it, however, seemed too sharp and pointed for that; in fact, I could very satisfactorily make out what the presentation was not. After a very careful examination, I discovered one ear, then the other, and huving passed up my finger as high as possible pos. teriorly, it came against the mouth. This at once satisfied me that it was a natural presentation, with some malformation, the only thing confusing about it being the great prominence of the eyes. In about a quarter of an hour, a female child was born, exhibiting the same peculiarities as in both the preceding cases. The child in other respects was a fine one, well nonrished, and had evidently not been dead long. The after-birth soon came away; and the patient is now going on well. I might mention that she had an abundant supply of milk, and that the breasts were very painful, so I thought it a favourable case to thy the belladonna as recommended by my esteemed friend $\mathrm{Dr}$. Goolden. Accordingly, on the third day, I painted a little of the extract with a feather around the nipple, as far as the areola extended, and on my visit the following morning, the result was almost miraculous. There was no milk; the breasts had resumed their ordinary size; and there was not a vestige of tendermess. She told me that the application had caused a slight smarting, but that in other respects she had felt no inconvenience.

Remarks. I cannot pretend to assign any cause for the curious lusus naturce exhibited in the foregoing cases. My friend $\mathrm{Mr}$. Beecroft, a retired medical man, residing in the village, saw the first and last cases I have related, and can testify to the difficulty caused in ascertaining correctly the presentation. I very much regret that in neither case was I able to secure the fortus for an accurate and satisfactory examination. It seems remathable that in all three cases, the malformation should have been of the same character, and that the children should in all other respects have been well formed, and have lived up to a very short time of their birth.

\section{EXPERINENTS UPON DOGS WHEN UNDER THE INFLUENCE OF STRYCHNIA, CONDUCTED BY THE LATE DR. MARSHALL IIALL.}

By Johx SLodxe, M.I., House-Surgeon to the Leicester Infirmary, etc.

Ir is well known that, some vears ago, Dr. Marshall IIall pro posed tracheotomy as a remedy in some forms of epilepsy and other allied convulsive affections. 'I'o quote his own words, "There are two cases of epilepsy in which the propriety and efficacy of tracheotomy admit of no doubt. The first of these is the cpilepsia laryngea, of inorganic origin, in its early stage, threatening mind or life, not yet involving organic change; that is spasmodic laryngismus and its effects. The same re mark applies to other convulsive diseases, puerperal convulsion inclusive. The second is the epilcpsia laryngea, proceeding to coma and paralytic laryngismus or stertor, aug. menting the coma, and endangering life. The same remark applies to coma left by other convulsive diseases, and to all kinds of simple apoplexy; that is, apoplexy without lesion or rupture of vessels, deep intoxication, narcotic poisoning, etc."

In May 1854, when visiting his relatives at Nottingham, Dr. Hall performed the following experiments at the General Hospital, in the presence of most of the medical men of the town, with the view of ascertaining the effects of tracheotomy upon dogs in which convulsions had been induced by strychnia. He stated that strychnia caused convulsions more closely re sembling epilepsy than any other agent with which he was acquainted; and he was of opinion that, by observing the effects of tracheotomy in the spasmodic paroxysms produced ly strychnia, much might be learned regarding the intiuence of his proposed remedy over epileptic convulsions. Dr. Hall directed, and seemed very much interested in, these experiments; and I can never forget the singular zeal and devotion of this distinguisbed man, whose recent death our profession and suffering humanity have to deplore; who, while aftlicted with an incurable disense, which forced him to relinquish a most lucrative practice, at a time, too, when he had achieved a world.ride reputation,-laboured perseveringly and most successfully to extend the boundaries of science. I had the honour of being requested to note the results of the ex periments, of which 1 shall proceed to give an abbreviated description.

$A$ tenth of a grain of ucetate of strychnia was given to a terrier bitch on a piece of meat. As no visible eftiects were produced in a quarter of an hour, the dose was repeated; but $ᄋ$ the strychnia this time was given in a pill made with mucilage. After the lapse of fiftecn minutes, spasmodic action began $N$ slightly; the tail was flexed, and drawn between the hind legs; $D$ and the animal walked about uneasily, with the nails protruded, so as to cuuse u rattling noise as she wandered over a boardell floor. In ten minutes she began to pant, with open $\mathbb{O}$ mouth, and assumed a position as if wearied with rumning. A $N$ minute afterwards, a tetanic spasm occurred, which shortly o passed off; and the log was placed on a table, over which she walked unsteadily for two minutes, when, by a sudden spasmodic action of the muscles generally, she was thrown from the $\mathbb{D}$ table. The tongue, in the fit, was livid. After it was over, she? generally kept lier mouth open, and panted; when the mouth 0 was closed, the panting ceased; she lay unon the table on her $\bar{O}$ side, with the legs extended. The respirations were 280 in the $\mathbb{D}$ minute; the pupils extremely dilated; but, upon cxamination four $\frac{}{\mathbb{Q}}$ minutes afterwards, they had become normal. Mr. Booth Eddi- $\varnothing$ son performed tracheotomy, after a method proposed by Dr.O Marshall Hall. The skin over the windpipe was drawn into a fold, and divided with a pair of scissors, of which both the inner and outer margins of the blades were sharpeued; buts there was a projecting shoulder upon the outer edge of thex blades, at a short distance from the points. The scissors were next passed between the rings of the trachea, and the handles drawn asunder. An instrument made of silver wire, of due strength, having been so bent alternately cight times, and united at its extreme points, as to form a tule-like cage, was 
then inserted into the opening, to keep it patent. Spasms continued during the operation. As $11 \mathrm{r}$. Eillison could not get the cage satisfactorily inserted, the edges of the opening in the trachea were kept asunder by a pair of clressing forceps. Ten miuutes after the operation, it was notel that there was a copious fluid secretion fluwing from the month; the spasms were less severe; the muscles not so rigid; panting continued. The wound was then closed with the fingers; dyspucea became more urgent; spasms increased. 'Three hours after the administration of the first dose of strychnin, with no tube on the trachea, the dog was in rigid geveral spasm; bead raised above back; fore legs extended at right angles with body ; hind legs drawn backwards; tail hung rather loosely; sometimes right hind leg remained for a short time relapsed, but was soon drawn out rigid again with a jerk. She would then lie comparatively relapsed for two or three minutes, till seized with another spasm, which usually continued for about two seconds, and quickly passed off. An increase of spasm could be excited and kept up by blowing on or touching the animal. A considerable quantity of watery fluid had fluwed from the mouth, and some urine had been passed. Towards death, the spasmodic rigidity gradually lessened, and the paroxysinal exacerbations became less prolonged. She died three hours and a half after having swallowed the first dose of strychnia. Shortly after death, the tongue was very livid, and the muscles were rigid. Twenty hours after death, there was some rigormortis. The right side of the heart contained much blood; the lower lobe of the right lung was engorged.

In the second experiment, the dog died in the first convul. sive fit, which was very severe, before the windpipe was opened. There was much rigor mortis the day after death.

On post mortem examination the right side of the heart was full. Both lungs were dark coloured and collapsed.

The third experiment did not differ very much from the first, except that the windpipe was opened, and the cage fixed in its place, by Mr. Thomas Wright, before the spasmcdic paroxysms began. During the convulsive attacks, it was olserved that the pupils dilated; when the muscles became relaxed and the breathing easy, the pupils contracted to the normal size. The value of an opening in the windpipe, in modifying the paroxysms, was tested in the following manuer. When a violent fit came on, a plug of sponge, which had been placed in the opening in the cage, was removed, and the fit lasted for fifty seconds afterwards. In a short time, the dog bad two other fits, decidedly less severe, and which lasted for a shorter time. The sponge was again inserted, and there was a series of jerks, succeeded by a severe fit, in which breathing was suspended for thirty seconds, very little for fifteen more, and then the dog appeared to be dead. The plug was re. moved, and almost immediately he began to revive; and, after passing through another fit, panting again came on. In the last fit, when the plug was out, suspension of respiration only lasted for five seconds. By a repeated resort to these expedients, and uniformly with similar results, the beneficial effect of a free opening in the trachea, in the spasmodic paroxysms produced by strychnia, was amply tested and proved. The dog died, however, with the cage in his windpipe, and the opening in it free. At the post mortem examination the right side of the heart was found to contain rather more blood than the left.

liesarks. The last experiment proves that, in the spasmodic convulsions produced by strychnia, there is some laryngeal ob. struction, as the paroxysms were miligated by the existence of a free opening in the windpipe. In a case of poisoning by strychnia, benefit would be derived from tracheotomy, although this operation alone would not appear to be sufficient to save the patient's life. 'The danger caused ly largncismus would be averted, but not the greater and fatal clanger arising from spasm of the respiratory muscles.

The manner in which strychnia destroys life is still a vexed question. Whether death is caused by exhaustion, by laryngismus, by spasm of the respiratory nuscles, or by fuilure of the heart's power, is not yet determined. Exhaustion could hardly have heen the cause of death in the dog the sulject of the second experiment, as more than five minutes did not clapse from the first seizure with tetanic spasms till his death. Laryngismus was not the cause of death in the dog last experi. mented upon, because, when he diel, there was a large and free opening in his trachea. Dr. lavy is of opinion, from experiments described in Guy s Iospital Reports, that death is always caused by aspliysia from spasm of the respira tory muscles. In a dog in which violent spasms had been induced by strychnia, he kept up artificial respiration for twenty minutes; and, during this period, the heart acted vigorously; but, when the respiration was discontiuued, the heart's action soon ceasel. He performed a similur experiment upon a rabbit with a like result; and he be. lieves, and I think rightly, that other observers failed to prolong life by artificial respiration, from not having remosed the inthenec of the strychuized museles by cutting through the cartilages of the ribs and opening the chest, so as to allow the lungs's to collapse and expel the air they contain. It would also appear from these experiments that strychmine has no direct effict upon the heart, and that its action is arrested because of the cessation of respiration. The right cavities of the heart, in the experiments which I have described, contained more blood than the left, inclicating death by asphyxia.

FATAL INVAGINATION OF COLON, ITC.

By. Joun 1. Nichorson, lisr., F.R.C.S., Stratfori Green.

I was called, on March $x$ th, 18:56, to sere a male child, eight months old, at the breast, that had never been ill until the last two days. On the evening of Narch 5th, it was laid down asleep by its mother, who soon afterwards heard an unusual shriek, and found that it had vomited. It kept crying, and drawing its legs up to the abdomen as if in pain. It took the breast eagerly, and romited; the milk curdled almost as soos us swallowed. The buwels had been moved twice during the day, and the motions appeared healthy. It now passed a small greenish motion without straining. One of Steedman's teething powders was given, but it was immediately rejected. The child continued crying and screaming during the night, and was carried in the morning to an intelligent practitioner, experienced in the treatment of children. He considered it to be a case of serous diarrha:a, and prescribed an aromatic chalk mixture. 'The symptoms continued unrelieved, and on the following evening, I found the child drowsy but unable to sleep owing to sudden seizures of pain, causing contortions of the face and jactitations of the extremities. It constantly retched, and vomited directly whatever was given to it. 'There was great prostration, a tendency to pallor and coldness of the surface, an exceedingly quick thready pulse, and dry brown tongue. Twice only during the day it had passed apparently without much effort a small quantity of a grumous slimy matter, a mixture of blood, serum and mucus, without a trace of feculent matter. The mother stated that nothing but this kind of matter had passed since the clild fell ill, with the exception of the greenish stool passed on the evening of March 0th.

'The nature of the case was not clear to me, but it appeared to possess more the symptoms of dysentery than of ordinary diarrhœa. I prescribed a warm bath, Dover's powler and grey powder, and a sedative mixt'ure. The ckild became more tranquil, and was thought better by its mother, but this arose from increasing exhaustion: it " as too prostrate to cry. The vomiting continued uualtered; there was no ablominal tenderness, nor perceptible enlargement; and the belly was normally plump and flaccid. An irruption of a profuse perspiration, a slight flush, apparently less suffering, aud involuntary discharge per anum, succeded, and death at last closed the scene after sixty hours of suffering.

Post mortem appearauces twenty-four hours after death. The lody wist fat and healihy. The abdomen was not distencled; there was about an ounce and a half of clear brown serous fluid in the pelvis. The peritoneum seemed softer than natural; but not a trace of lymph nor other inflammatory product was observed. 'The bowels generally were empty; and, more especially below the umbilicus, redder than usual.

The colon was only to le found on the left side, and before reaching the sigmoid thesure for about ten or twelve inches this gut appeared to be distended with frecal matter, which stopped abruptly just above the point where it enters the pelvis. The uplex and midlle fortions of this obstructing body were thirkest, and at its termination it gradually contracted into a round point. On tracing the colon upwards, its transverse portion was apparently twisted upon itself, so as to drag down the gall-bladder and hepatic ressels and duct. Here the ascending colon was lost to view, and not a trace of it could be seen on the right side. A part of the ileum, the whole of the esecum, the ascending and part of the transverse portion of the colon were invaginated, and where the gut was apparently twisted upon itself was the commencement of the inversion. The linger could be passed into this cpening down the side of the gut as it passed within. The 